\title{
Effect of Achillea millefolium aqueous extract on memory deficit and anxiety caused by stroke in ovariectomized rats
}

\author{
Gila Pirzad Jahromi ${ }^{*}{ }^{\mathbb{D}}$, Esmail Imani $^{2}$, Mohammad Nasehi $^{3}$, Alireza Shahriari $^{2^{*}}$ \\ ${ }^{1}$ Neuroscience Research Centre, Baqiyatallah University of Medical Sciences, Tehran, Iran \\ ${ }^{2}$ Chemical Injuries Research Center, System Biology and Poisonings Institute, Baqiyatallah University of Medical Sciences, Tehran, Iran \\ ${ }^{3}$ Cognitive and Neuroscience Research Center (CNRC), Tehran Medical Sciences Branch, Islamic Azad University, Tehran, Iran
}

\section{A R T I C L E I N F O}

Article Type:

Original Article

\section{Article History:}

Received: 26 September 2018

Accepted: 2 January 2019

\section{Keywords:}

Achillea millefolium

Cerebral ischemia

Memory

Anxiety

Ovariectomy

\begin{abstract}
A B S T R A C T
Introduction: Some studies indicated that the decrease of estrogen level in menopausal woman results in increasing the risk of stroke. Although estrogen is a neuroprotective factor, high consumption of this compound may develop breast cancer and endometriosis. The present study investigated the effect of Achilles millefolium extract, containing estrogenlike compounds, on memory impairment and anxiogenic-like behaviors caused by cerebral ischemia in ovariectomized rats.

Methods: Permanent middle cerebral artery ligation was performed, as a model for studying postmenopausal condition, in 48 female Wistar rats weighing 200-250 g. The aqueous extract of A. millefolium was prepared and gavaged for 4 weeks after inducing cerebral ischemia. Memory and anxiety-like behavior assessments were evaluated by step-through and elevated plus maze apparatus, respectively.

Result: According to the results, cerebral ischemia in ovariectomized rats induced amnesia and anxiogenic-like behaviors which were restored by $7 \mathrm{mg} / \mathrm{kg}$ of A. millefolium aqueous extract. Furthermore, inactivation of estrogen receptors (ERs) by tamoxifen $(100 \mu \mathrm{g} / \mathrm{kg}$, intraperitoneally) blocked the restoration effect of $A$. millefolium on behaviors induced by cerebral ischemia.

Conclusion: It could be concluded that, oral administration of A. millefolium extract is able to restore memory impairment and anxiogenic-like behaviors induced by ischemia via ERs in ovariectomized rat.
\end{abstract}

Implication for health policy/practice/research/medical education:

Achillea millefolium aqueous extract leads to improvement of memory deficit and anxiety caused by cerebral ischemia. The results showed that $A$. millefolium might be effective in complications of stroke.

Please cite this paper as: Pirzad Jahromi G, Imani E, Nasehi M, Shahriari A. Effect of Achillea millefolium aqueous extract on memory deficit and anxiety caused by stroke in ovariectomized rats. J Herbmed Pharmacol. 2019;8(2):153-159. doi: 10.15171/ jhp.2019.24.

\section{Introduction}

One of the main causes of death or incapability in the developed countries is ischemic stroke In fact, progressive aging of the population in these countries has resulted in the incidence of stroke, increasingly (1). The harmful effects of cerebral ischemia include inflammation, apoptosis, oxidative stress, acidosis and necrosis (2-4) Partial paralysis as well as the difficulties with memory, thinking, language, movements (5) and anxiety (6) can be considered as other deficits.

Gender differences are important factors in the process of stroke due to the presence or absence of estrogen (7). Different studies have confirmed that an important neuroprotective agent in many models of brain injury like stroke is estrogen (8). Many studied conducted recently proved the claim that estrogens have neuroprotective effects in a variety of focal and global ischemia models (9). Notably, a powerful feminizing hormone such as 17 betaestradiol (E2) in a host of cell and animal models of stroke and neurodegenerative diseases has been also shown to have neuroprotective effects (10). Recently, clinical studies indicated the possibility of occurring some negative health 
consequences following hormone therapies of diseases like breast cancer (11) and endometriosis (12). Therefore, using phytoestrogens, natural nonsteroidal plant-derived compounds with estrogen-like molecules, may alter the concentration of estrogen level (13).

Yarrow (Achillea millefolium) is a plant with phytoestrogen properties (14) which belongs to the Asteraceae family growing wild all across the Europe, Asia, North Africa and North America. Notably, it is extensively applied in Italian folk medicine (15). For instance, Italians widely use special teas prepared from the aerial parts of yarrow as a traditional treatment of spasms, menstrual pain, digestive complaints and other ailments (14). Taking the results of epidemiological studies into account, it has been suggested that dietary phytoestrogen intake might have a protective role in hormone-dependent cancers, especially breast cancer (16). Phytoestrogens are able to selectively bind to classical estrogen receptors (ERs) and regulate gene expression mediated by estrogen response elements (17). It should be noted that not only do they bind to ERs, but also exert potent antioxidant activity (17). Therefore, an intensive research has been recently conducted on phytoestrogens (18). The aim of this study was to investigate the effect of $A$. millefolium extract on memory impairment and anxiety caused by cerebral ischemia with middle cerebral artery occlusion in ovariectomized rats (OVX).

\section{Materials and Methods}

In this study, 48 female Wistar rats were used weighting 200 to 250 g. Animals were classified into 6 groups, considering eight animals in each group. They were maintained at $25 \pm 2{ }^{\circ} \mathrm{C}$ under 12 -hour light/dark cycle with free access to food.

\section{Preparation of extracts}

Achillea millefolium's flowers were used to prepare the extract. So that the branches of the plant from the Herbarium of Isfahan University were purchased (Herbarium approval number is 7757) (19). The tops and leaves of it were separated and washed. Then, they were dried thoroughly in a suitable environment at room's temperature $\left(25^{\circ} \mathrm{C}\right)$. After grinding, $3 \mathrm{~g}$ of plant powder was added to $150 \mathrm{~mL}$ of distilled water with a Soxhlet system. After that, the aqueous extract was separated by a rotary machine (20). The selective dose in this study was $200 \mathrm{mg} / \mathrm{kg}$, based on previous studies $(19,21)$. Due to the fact that the most of rat weighed around $250 \mathrm{~g}$, we converted the mentioned dose per rat $(3.5,7 \mathrm{mg} / \mathrm{rat})$ $(19,21)$.

Ovariectomization (menopause induction)

For anesthesia, animals received intraperitoneally a mixed solution of ketamine and xylazine at a dose of $75 \mathrm{mg} / \mathrm{kg}$ and $10 \mathrm{mg} / \mathrm{kg}$, respectively. After that, they were shaved and their abdomen area was sterilized. Then, a gap of 1 to $2 \mathrm{~cm}$ was created in abdomen area and the ovarian was removed by a cautery device. The inner and outer layers were then sutured, separately. Finally, the Penicillin was injected into the thigh muscle of the rat at a dose of $0.3 \mathrm{mg}$ $/ 100 \mathrm{~g}$ animal's weight and the animal was returned to the cage for surgical recovery (22).

Accurate assessment of ovariectomized rat

After 3 days, vaginal smears were prepared from the ovariectomized animals for 6 days and observed under an optical microscope. In this research, lack of ferns represents the true ovariectomy (22).

\section{Creation of ischemia}

After anesthetizing the animals using $75 \mathrm{mg} / \mathrm{kg}$ of ketamine and $10 \mathrm{mg} / \mathrm{kg}$ of xylazine intraperitoneally, the animals were beveled $2 \mathrm{~cm}$ between their eyes and ears. After removing the skin and temporalis muscle, the bones were removed and the middle cerebral artery was burned with cautery device. Finally, after returning soft tissues to their place, the skin was sutured (23).

The rats were categorized in different groups as follows:

1. Sham group on which all surgical stages were done without any damage to the ovaries (non-surgical ovariectomy were gavaged with saline for one month without any injury to the middle cerebral artery).

2. Control group on which the ovariectomized surgery was performed. After one week, they were gavaged with saline for one month

3. A. millefolium 3.5 group on which the ovariectomized surgery was performed. After one week, the extract of plant was gavaged with $3.5 \mathrm{mg} / \mathrm{kg}$ of A. millefolium for 1 month.

4. A. millefolium 7 group on which the ovariectomized surgery was performed. After one week, the plant's extract was gavaged with $7 \mathrm{mg} / \mathrm{kg}$ of A. millefolium for 1 month.

5. Tamoxifen group on which the ovariectomized surgery was performed. After one week, they were gavaged with $100 \mu \mathrm{g} / \mathrm{kg}$ of tamoxifen for 4 weeks.

6. A. millefolium 7+ tamoxifen group on which the ovariectomized surgery was performed. After one week, the plant's extract was gavaged with $7 \mathrm{mg} / \mathrm{kg}$ of A. millefolium and $100 \mu \mathrm{g} / \mathrm{kg}$ of tamoxifen.

Behavioral test

Passive avoidance test

The passive avoidance task was evaluated 1 week after stroke using two-way shuttle box consisting of two near Plexiglas compartments in the same size $(30 \times 20 \times 20$ $\mathrm{cm})$ with grid floors covered with stainless steel bars $(2$ $\mathrm{mm}$ ) (24). In order to avoid training, each rat was given a 10-minute adaptation period with free access to the light or dark compartment. On the second day and after placing 
the animals in a shuttle-box, they were placed into the illuminated compartment. Ten seconds later, the sliding door was raised. Initial latency was recorded as learning phase. Entering the dark compartment, the door was closed and the animal's fore and hind paws were exposed to an electrical shock $(0.3 \mathrm{~mA}, 50 \mathrm{~Hz})$ for 3 seconds. Then, the rat was returned to the home cage. 24 hours later, the rat was placed into the illuminated compartment to test short-term memory. The sliding door was then raised 5 seconds later. The latency of entering the dark compartment was recorded as memory test (step-through latency). The maximum time considered in this procedure was 300 seconds (25).

\section{Elevated plus maze test}

The anxiety was measured 5 days after stroke using an elevated plus maze, a platform with two enclosed and two open arms (26). The elevated plus maze works based on rats' natural detestation of open spaces, which causes behaviors involving the avoidance of open areas through limiting movements to a bounded space or its edges. This apparatus consists of two opposing closed arms $(50 \times 10 \times 40 \mathrm{~cm})$ and two opposing open arms $(50 \times 10$ $\mathrm{cm})$ connected to a center platform $(10 \times 10 \mathrm{~cm})$. Where these 4 arms intersect, the maze is elevated $50 \mathrm{~cm}$ above the floor, with a square platform of $10 \times 10 \mathrm{~cm}$. After placing the rats in the center of the maze, their activity were videotaped for 5 minutes. Anxiety reduction in the plus-maze was shown by an increase in the percentage of time weaken in the open arms (\%OAT $=$ time in open arms/ total time in open or closed arms $\times 100$ ), and an increase in the percentage of entries into the open arms $(\% \mathrm{OAE}=$ entries into open arms/total entries into open or closed arms $\times 100)(27)$.
Statistical analysis

Graphs were plotted using SigmaPlot software and data were obtained by SPSS, using significant F-value, oneway analysis of variance (ANOVA), Tukey post hoc test and $t$ test for comparison between groups. $P<0.05$ was considered statistically significant between experimental groups.

\section{Results}

The effect of A. millefolium on amnesia induced by stroke in the absence and presence of tamoxifen

Independent $t$ test showed that stroke destroyed memory formation, compared to sham group $\left(\mathrm{t}_{12}=6 ; P<0.001\right)$. One-way ANOVA and Tukey post hoc test showed that $100 \mu \mathrm{g} / \mathrm{kg}$ of tamoxifen and $3.5 \mathrm{mg} / \mathrm{kg}$ of $A$. millefolium did not alter amnesia induced by stroke, while A. millefolium at a higher dose $(7 \mathrm{mg} / \mathrm{kg})$ restored this phenomenon $[\mathrm{F}(3,24)=12, P<0.01]$. Moreover, independent $t$ test demonstrated that inactivation of ERs by tamoxifen blocked the restoration effect of $A$. millefolium on strokeinduced amnesia $\left(\mathrm{t}_{12}=2 ; P<0.05\right)$ (Figure 1).

The effect of $A$. millefolium on anxiogenic-like behavior (\%OAT) induced by stroke in the absence and presence of tamoxifen

Independent $t$ test showed that stroke decreased OAT\% $\left(\mathrm{t}_{12}=6 ; P<0.001\right.$, Figure 2A), OAE $\%\left(\mathrm{t}_{12}=6.1 ; P<0.001\right.$, Figure $2 \mathrm{~B})$ and locomotor activity $\left(\mathrm{t}_{12}=6 ; P<0.001\right.$, Figure $2 \mathrm{C})$. One-way ANOVA and Tukey post hoc test showed that tamoxifen at a dose of $100 \mu \mathrm{g} / \mathrm{kg}$ and A. millefolium at a dose of $3.5 \mathrm{mg} / \mathrm{kg}$ did not alter OAT\%, OAE\% and locomotor activity induced by stroke, while A. millefolium at a higher dose $(7 \mathrm{mg} / \mathrm{k})$ restored $\mathrm{OAT} \%[\mathrm{~F}(3,28)=4.91$, $P<0.01$, Figure $2 \mathrm{~A}]$, OAE\% $[\mathrm{F}(3,28)=3.07, P<0.01$,

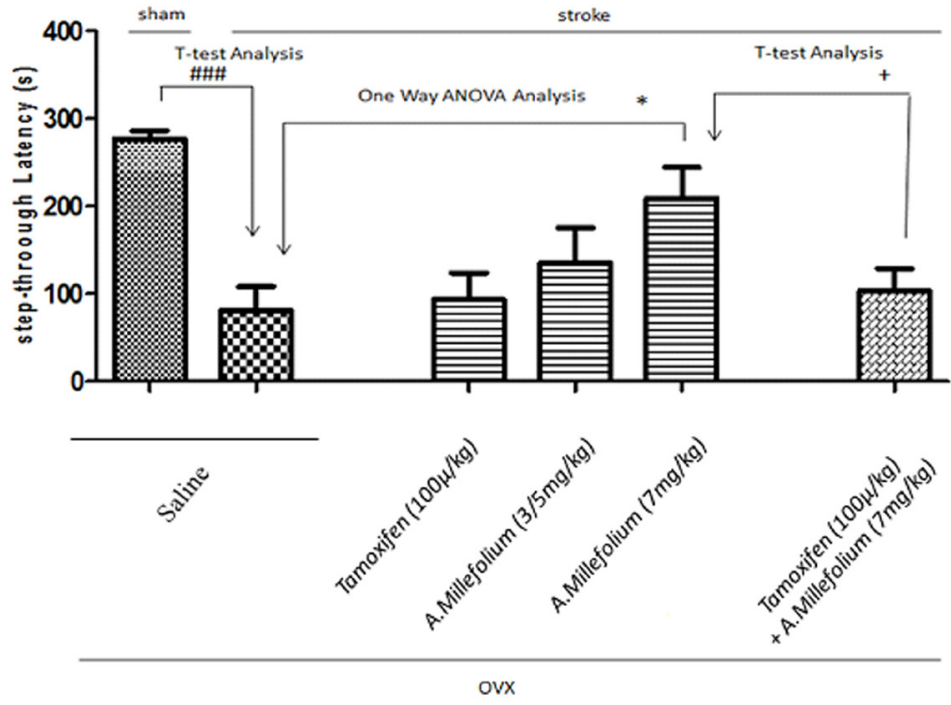

Figure 1. The effect of tamoxifen $(100 \mu \mathrm{g} / \mathrm{kg})$ in the presence and absence of $A$. millefolium (3.5 and $7 \mathrm{mg} / \mathrm{kg})$ on memory. The stroke animals received saline $(10 \mathrm{~mL} / \mathrm{kg})$, tamoxifen $(100 \mu \mathrm{g} / \mathrm{kg})$, . millefolium (3.5 and $7 \mathrm{mg} / \mathrm{kg})$, tamoxifen $(100 \mu \mathrm{g} / \mathrm{kg}) \mathrm{plus} A$. millefolium $(7 \mathrm{mg} / \mathrm{kg})$. \#\# P<0.001 compared to sham group. ${ }^{*} P<0.5$ compared to stroke group. $+P<0.5$ significant difference with $A$. millefolium $(7 \mathrm{mg} / \mathrm{kg}) \mathrm{group}$. 
Figure $2 \mathrm{~B}]$ and hyperlocomotion $[\mathrm{F}(3,28)=8.79, P<0.01$, Figure 2C] induced by stroke. Moreover, independent t-test demonstrated that inactivation of ERs by tamoxifen blocked the restoration effect of A. millefolium on OAT\% $\left(\mathrm{t}_{12}=2 ; P<0.05\right)$ and locomotor activity $\left(\mathrm{t}_{12}=2 ; P<0.05\right)$ but not OAE $\left(\mathrm{t}_{12}=2 ; P<0.05\right)$ (Figure 2 ).

\section{Discussion}

According to our results, it can be concluded that cerebral ischemia causes cognitive deficits. In a previous study, memory impairment occurred after induction of ischemia (28). In fact, reduced estrogen at menopause leads to a wide range of symptoms such as memory disorders and anxiety (6). Besides that, it is shown that deficits of learning and memory (29), sensation, perception and intellect (30) can be caused by ischemia events. Notably, overproduction of reactive oxygen species in mitochondria occurs as a result of reperfusion after ischemia. In addition, when these radicals consume endogenous antioxidants, a dramatic rise occurs in intracellular reactive oxygen species. It is together with a reaction of cellular macromolecules such as lipids, proteins and nucleic acids which results in oxidative damage of the neurons (31). Previous studies showed that the down-regulation of ER $\alpha$ and ER $\beta$ in the cerebral cortex may contribute to the loss of estrogen efficacy against ischemic injury in aged females (32). Estradiol and estrogen-like compounds are powerful neuroprotective agents in vivo and in vitro against apoptotic stimuli including experimental stroke (33). It is now well established that estrogen is a protective factor against focal cerebral ischemia and the global cerebral ischemia (34). It acts as a transcriptional activator through two nuclear receptor isoforms, ER $\alpha$ and ER $\beta$. Both receptors are present in the brain and display overlapping and distinct distributions (35). In vivo, the neuroprotective actions of estrogen in cerebral ischemia have been attributed to the ER subtype activation (36) using ERa and ER $\beta$ knockout mice, although both isoforms can be neuroprotective in vitro (37). More investigations on the role of a periodic ER- $\beta$ agonist regimen demonstrated that reduction of the innate immune response in the brain could help reduce the incidence of global cerebral ischemia and lessen its impact in post-menopausal women (38). Using estrogen increases the risk of catching breast cancer and endometriosis (39).

Phytoestrogens can be naturally found in plant-derived compounds, structurally related to the gonadal steroid, $17 \beta$-estradiol, which are present in the human diet (40). According to the recent progress in pharmaceuticals, the development of selective ER modulators might bring about lots of estrogen's advantageous effects without suffering from detrimental side effects. However, many women today assume using complementary and alternative therapies beneficial for menopausal symptoms and use high soy diets or soy isoflavone supplements (41). It is needless to say that physiologically achievable doses
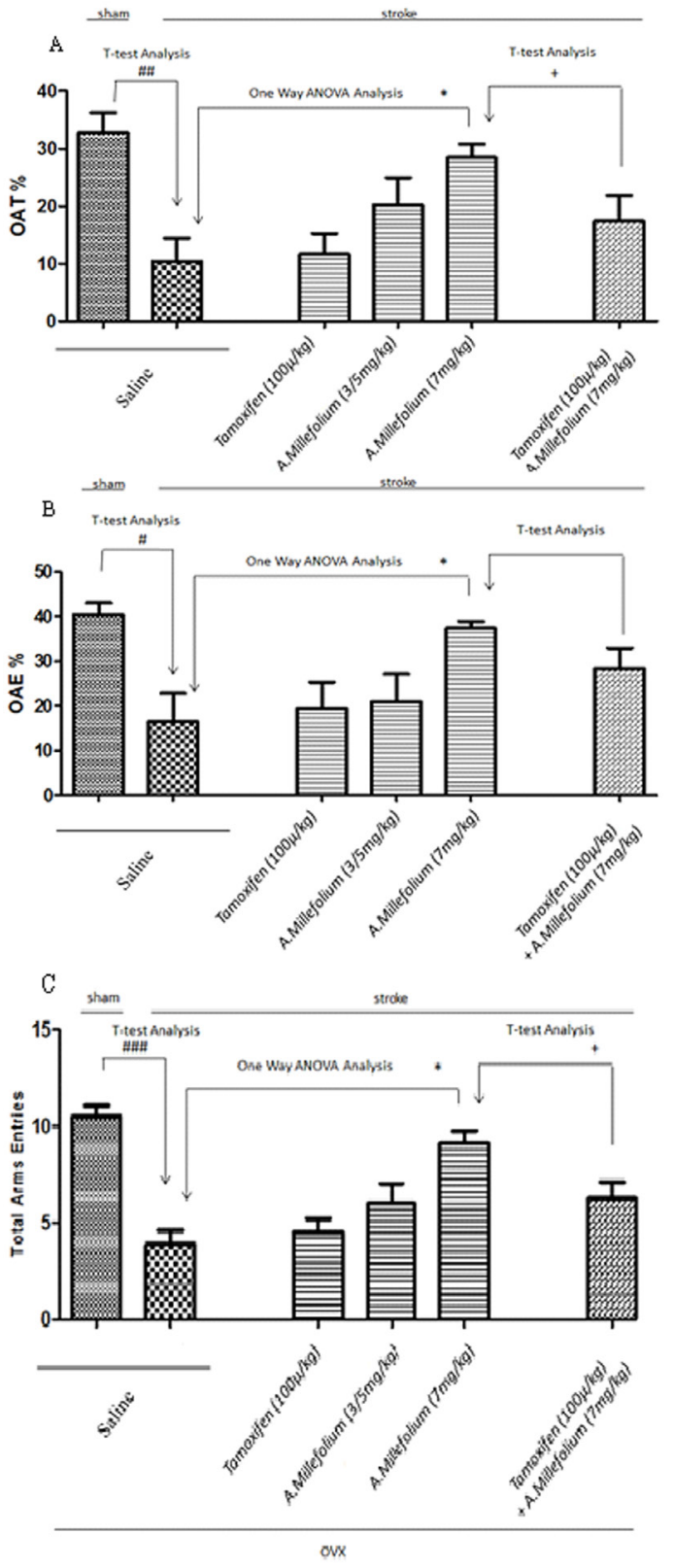

Figure 2. The effect of Tamoxifen $(100 \mu \mathrm{g} / \mathrm{kg})$ in the presence and absence of $A$. millefolium $(3.5$ and $7 \mathrm{mg} / \mathrm{kg})$ on anxiety-like behaviors including OAT\% (panel A), OAE\% (panel B) and locomotion (panel C). The srtoke animals received saline $(10 \mathrm{~mL} / \mathrm{kg})$, tamoxifen $(100 \mu \mathrm{g} / \mathrm{kg})$, A. millefolium (3.5 and $7 \mathrm{mg} / \mathrm{kg})$, tamoxifen $(100 \mu \mathrm{g} / \mathrm{kg})$ plus $A$. millefolium $(7 \mathrm{mg} / \mathrm{kg})$. \# $P<0.05$, \#\# $P<0.01$, \#\# $P<0.001$ compared to sham group. ${ }^{*} P<0.5$ compared to stroke group. $+P<0.5$ significant difference with $A$. millefolium (7 mg/kg) group.

of isoflavones, behaving as phytoestrogens, are able to simulate some of the neuroprotective effects of estrogens (42).

Achillea millefolium has estrogen-like activity and contains compounds of apigenin and luteolin. Apigenin could stimulate estrogen-receptor pathways and ERs (ERa and $\operatorname{ER} \beta$ ). Luteolin also stimulates the beta receptor (14).

The results of this study demonstrated a decrease in memory deficit and anxiogenic-like behavior of 
ovariectomized rats which orally received $A$. millefolium extract $(7 \mathrm{mg} / \mathrm{kg}$ ) during 4 weeks after inducing stroke. According to previous studies, consuming dietary soy containing estrogen-like compounds has neuroprotective effects on brain ischemia (42). In addition, it has been previously shown that genistein is a phytoestrogen compound which is protective to brain against cerebral ischemia through reducing oxidative stress and neuronal degeneration (43). Daidzein as a phytoestrogen compound also exhibits neuroprotective effects on ischemic brain tissue (44). In addition, coumestrol is a phytoestrogen compound which has potential benefits for either prevention or therapeutics use against cerebral ischemia in males (45). In another study, it has been demonstrated that Soy dietary may play a role in the brain injury (46). Soy prevents memory impairment and brain tissue oxidative damage caused by ischemia in OVX rats (47). Therefore, it is determined that $A$. millefolium extract reduces memory impairment due to having antioxidant and estrogen-like compounds, which is consistent with previous results. In in vitro studies, it has also been shown that pretreatment with dietary levels of Soy phytoestrogens protects primary cortical neurons from ischemic-like injury (48). Apparently, in order to inhibit apoptotic cell death, the isoflavones use the same ER-kinase pathway as estrogen (48). Since plant compounds may also have complications; therefore, it is necessary to do more research on the side effects of these plants.

\section{Conclusion}

This study showed that, due to estrogen-like compounds and antioxidant, the gavage of $A$. millefolium extract could result in the improvement of memory impairments and anxiogenic-like behavior induced by cerebral ischemia caused by the middle cerebral artery occlusion.

\section{Acknowledgments}

The authors would like to thank the staff of laboratory of Cognitive and Neuroscience Research Center (CNRC), Tehran Medical Sciences Branch, Islamic Azad University, Tehran, Iran.

\section{Authors' contributions}

All authors have contributed in this study in terms of study design, experimental work, statistical analysis, scientific writing and revisions. All confirmed the final version of the manuscript for publication.

\section{Conflict of interests}

The authors declared there is no conflict of interest.

\section{Ethical considerations}

The present study was approved by the ethics committee of Baqiyatallah University of Medical Sciences, Tehran, Iran (ID: IR.BMSU.REC.1396.585).

\section{References}

1. Kleindorfer $\mathrm{D}, \mathrm{Xu} \mathrm{Y}$, Moomaw CJ, Khatri P, Adeoye $\mathrm{O}$, Hornung R. US geographic distribution of rt-PA utilization by hospital for acute ischemic stroke. Stroke. 2009;40(11):3580-4. doi: 10.1161/strokeaha.109.554626.

2. Pirzad Jahromi G, Shabanzadeh Pirsaraei A, Mokhtari Hashtjini M, Sadr SS, Rasouli Vani J, Raouf Sarshoori J, et al. Bone marrow-derived mesenchymal stem cell and simvastatin treatment leads to improved functional recovery and modified c-Fos expression levels in the brain following ischemic stroke. Iran J Basic Med Sci. 2018;21(10):1004-12. doi: $10.22038 / \mathrm{ijbms} .2018 .29382 .7100$.

3. Pirzad Jahromi G, Seidi S, Sadr SS, Shabanzadeh Pirsaraei A, Keshavarz M, Kaka GR, et al. Therapeutic effects of a combinatorial treatment of simvastatin and bone marrow stromal cells on experimental embolic stroke. Basic Clin Pharmacol Toxicol. 2012;110(6):487-93. doi: 10.1111/j.1742-7843.2011.00848.x.

4. Pirzad Jahromi G, Shabanzadeh Pirsaraei A, Sadr SS, Kaka G, Jafari M, Seidi S, et al. Multipotent bone marrow stromal cell therapy promotes endogenous cell proliferation following ischemic stroke. Clin Exp Pharmacol Physiol. 2015;42(11):1158-67. doi: 10.1111/1440-1681.12466.

5. Lambertsen KL, Biber K, Finsen B. Inflammatory cytokines in experimental and human stroke. J Cereb Blood Flow Metab. 2012;32(9):1677-98. doi: 10.1038/jcbfm.2012.88.

6. Hardy R, Kuh D. Change in psychological and vasomotor symptom reporting during the menopause. Soc Sci Med. 2002;55(11):1975-88.

7. Chinwatanakul S, Boonyapisit K, Pornsriniyom D, Proyoonwiwat N, Senanarong V, Chaisevikul R, et al. Siriraj Acute Stroke Unit: 10 years experience. J Med Assoc Thai. 2012;95 Suppl 2:S235-44.

8. Alonso de Lecinana M, Egido JA. Estrogens as neuroprotectants against ischemic stroke. Cerebrovasc Dis. 2006;21 Suppl 2:48-53. doi: 10.1159/000091703.

9. Lebesgue D, Traub M, De Butte-Smith M, Chen C, Zukin RS, Kelly MJ, et al. Acute administration of non-classical estrogen receptor agonists attenuates ischemia-induced hippocampal neuron loss in middle-aged female rats. PLoS One. 2010;5(1):e8642. doi: 10.1371/journal.pone.0008642.

10. Simpkins JW, Dykens JA. Mitochondrial mechanisms of estrogen neuroprotection. Brain Res Rev. 2008;57(2):42130. doi: 10.1016/j.brainresrev.2007.04.007.

11. Folkerd E, Dowsett M. Sex hormones and breast cancer risk and prognosis. Breast. 2013;22 Suppl 2:S38-43. doi: 10.1016/j.breast.2013.07.007.

12. Han SJ, Jung SY, Wu SP, Hawkins SM, Park MJ, Kyo S, et al. Estrogen receptor beta modulates apoptosis complexes and the inflammasome to drive the pathogenesis of endometriosis. Cell. 2015;163(4):960-74. doi: 10.1016/j. cell.2015.10.034.

13. Kuiper GG, Lemmen JG, Carlsson B, Corton JC, Safe $\mathrm{SH}$, van der Saag PT, et al. Interaction of estrogenic chemicals and phytoestrogens with estrogen receptor beta. Endocrinology. 1998;139(10):4252-63. doi: 10.1210/ endo.139.10.6216.

14. Innocenti G, Vegeto E, Dall'Acqua S, Ciana P, Giorgetti M, Agradi E, et al. In vitro estrogenic activity of Achillea millefolium L. Phytomedicine. 2007;14(2-3):147-52. doi: 
10.1016/j.phymed.2006.05.005.

15. Benedek B, Kopp B. Achillea millefolium L. s.l. revisited: recent findings confirm the traditional use. Wien Med Wochenschr. 2007;157(13-14):312-4. doi: 10.1007/s10354007-0431-9.

16. Adlercreutz H. Phyto-oestrogens and cancer. Lancet Oncol. 2002;3(6):364-73.

17. Zhao L, Chen Q, Diaz Brinton R. Neuroprotective and neurotrophic efficacy of phytoestrogens in cultured hippocampal neurons. Exp Biol Med (Maywood). 2002;227(7):509-19.

18. Lephart ED, Thompson JM, Setchell KD, Adlercreutz $\mathrm{H}$, Weber KS. Phytoestrogens decrease brain calciumbinding proteins but do not alter hypothalamic androgen metabolizing enzymes in adult male rats. Brain Res. 2000;859(1):123-31.

19. Vazirinejad R, Ayoobi F, Arababadi MK, Eftekharian MM, Darekordi A, Goudarzvand M, et al. Effect of aqueous extract of Achillea millefolium on the development of experimental autoimmune encephalomyelitis in C57BL/6 mice. Indian J Pharmacol. 2014;46(3):303-8. doi: 10.4103/0253-7613.132168.

20. Guo YP, Saukel J, Mittermayr R, Ehrendorfer F. AFLP analyses demonstrate genetic divergence, hybridization, and multiple polyploidization in the evolution of Achillea (Asteraceae-Anthemideae). New Phytol. 2005;166(1):27389. doi: 10.1111/j.1469-8137.2005.01315.x.

21. Ayoobi F, Roohbakhsh A, Allahtavakoli M, Vazirinejad R, Rajabi S, Shamsizadeh A. Achillea millefolium aqueous extract does not impair recognition memory in mice. Trop J Pharm Res. 2013;12(2):209-13. doi: 10.4314/tjpr.v12i2.12.

22. Li H, Li SL, Wu ZH, Gong L, Wang JL, Li YZ. Effect of traditional Chinese herbal Bu-Wang-San on synaptic plasticity in ovariectomised rats. J Pharm Pharmacol. 2009;61(1):95-101. doi: 10.1211/jpp/61.01.0013.

23. Bogaert-Buchmann A, Poittevin M, Po C, Dupont D, Sebrie C, Tomita Y, et al. Spatial and temporal MRI profile of ischemic tissue after the acute stages of a permanent mouse model of stroke. Open Neuroimag J. 2013;7:4-14. doi: $10.2174 / 1874440001307010004$.

24. Tamburella A, Micale V, Mazzola C, Salomone S, Drago F. The selective norepinephrine reuptake inhibitor atomoxetine counteracts behavioral impairments in trimethyltin-intoxicated rats. Eur J Pharmacol. 2012;683(13):148-54. doi: 10.1016/j.ejphar.2012.02.045.

25. Rachmany L, Tweedie D, Li Y, Rubovitch V, Holloway HW, Miller J, et al. Exendin-4 induced glucagon-like peptide-1 receptor activation reverses behavioral impairments of mild traumatic brain injury in mice. Age (Dordr). 2013;35(5):1621-36. doi: 10.1007/s11357-012-9464-0.

26. Nemeth CL, Reddy R, Bekhbat M, Bailey J, Neigh GN. Microglial activation occurs in the absence of anxiety-like behavior following microembolic stroke in female, but not male, rats. J Neuroinflammation. 2014;11:174. doi: 10.1186/ s12974-014-0174-7.

27. Valizadegan F, Oryan S, Nasehi M, Zarrindast MR. Interaction between morphine and noradrenergic system of basolateral amygdala on anxiety and memory in the elevated plus-maze test based on a test-retest paradigm. Arch Iran Med. 2013;16(5):281-7. doi: 013165/aim.008.
28. Fonteles AA, de Souza CM, de Sousa Neves JC, Menezes AP, Santos do Carmo MR, Fernandes FD, et al. Rosmarinic acid prevents against memory deficits in ischemic mice. Behav Brain Res. 2016;297:91-103. doi: 10.1016/j.bbr.2015.09.029.

29. Cechetti F, Worm PV, Elsner VR, Bertoldi K, Sanches E, Ben J, et al. Forced treadmill exercise prevents oxidative stress and memory deficits following chronic cerebral hypoperfusion in the rat. Neurobiol Learn Mem. 2012;97(1):90-6. doi: 10.1016/j.nlm.2011.09.008.

30. Carmichael ST. Plasticity of cortical projections after stroke. Neuroscientist. 2003;9(1):64-75. doi: $10.1177 / 1073858402239592$.

31. Negishi H, Ikeda K, Nara Y, Yamori Y. Increased hydroxyl radicals in the hippocampus of stroke-prone spontaneously hypertensive rats during transient ischemia and recirculation. Neurosci Lett. 2001;306(3):206-8.

32. Cai M, Ma YL, Qin P, Li Y, Zhang LX, Nie H, et al. The loss of estrogen efficacy against cerebral ischemia in aged postmenopausal female mice. Neurosci Lett. 2014;558:1159. doi: 10.1016/j.neulet.2013.11.007.

33. Gibson CL, Gray LJ, Murphy SP, Bath PM. Estrogens and experimental ischemic stroke: a systematic review. J Cereb Blood Flow Metab. 2006;26(9):1103-13. doi: 10.1038/ sj.jcbfm.9600270.

34. Etgen AM, Jover-Mengual T, Zukin RS. Neuroprotective actions of estradiol and novel estrogen analogs in ischemia: translational implications. Front Neuroendocrinol. 2011;32(3):336-52. doi: 10.1016/j.yfrne.2010.12.005.

35. Shughrue PJ, Merchenthaler I. Distribution of estrogen receptor beta immunoreactivity in the rat central nervous system. J Comp Neurol. 2001;436(1):64-81.

36. Dubal DB, Zhu H, Yu J, Rau SW, Shughrue PJ, Merchenthaler I, et al. Estrogen receptor alpha, not beta, is a critical link in estradiol-mediated protection against brain injury. Proc Natl Acad Sci U S A. 2001;98(4):1952-7. doi: 10.1073/ pnas.041483198.

37. Fitzpatrick JL, Mize AL, Wade CB, Harris JA, Shapiro RA, Dorsa DM. Estrogen-mediated neuroprotection against beta-amyloid toxicity requires expression of estrogen receptor alpha or beta and activation of the MAPK pathway. J Neurochem. 2002;82(3):674-82.

38. de Rivero Vaccari JP, Patel HH, Brand FJ 3rd, Perez-Pinzon MA, Bramlett HM, Raval AP. Estrogen receptor beta signaling alters cellular inflammasomes activity after global cerebral ischemia in reproductively senescence female rats. J Neurochem. 2016;136(3):492-6. doi: 10.1111/jnc.13404.

39. Lipovac M, Chedraui P, Gruenhut C, Gocan A, Stammler M, Imhof M. Improvement of postmenopausal depressive and anxiety symptoms after treatment with isoflavones derived from red clover extracts. Maturitas. 2010;65(3):258-61. doi: 10.1016/j.maturitas.2009.10.014.

40. Toran-Allerand CD. Minireview: A plethora of estrogen receptors in the brain: where will it end? Endocrinology. 2004;145(3):1069-74. doi: 10.1210/en.2003-1462.

41. Wathen $\mathrm{CN}$. Alternatives to hormone replacement therapy: a multi-method study of women's experiences. Complement Ther Med. 2006;14(3):185-92. doi: 10.1016/j. ctim.2005.11.003.

42. Burguete MC, Torregrosa G, Perez-Asensio FJ, CastelloRuiz M, Salom JB, Gil JV, et al. Dietary phytoestrogens 
improve stroke outcome after transient focal cerebral ischemia in rats. Eur J Neurosci. 2006;23(3):703-10. doi: 10.1111/j.1460-9568.2006.04599.x.

43. Aras $A B$, Guven $M$, Akman $T$, Alacam H, Kalkan $Y$, Silan C, et al. Genistein exerts neuroprotective effect on focal cerebral ischemia injury in rats. Inflammation. 2015;38(3):1311-21. doi: 10.1007/s10753-014-0102-0.

44. Aras AB, Guven M, Akman T, Ozkan A, Sen HM, Duz U, et al. Neuroprotective effects of daidzein on focal cerebral ischemia injury in rats. Neural Regen Res. 2015;10(1):14652. doi: 10.4103/1673-5374.150724.

45. Castro CC, Pagnussat AS, Moura N, da Cunha MJ, Machado FR, Wyse AT, et al. Coumestrol treatment prevents $\mathrm{Na}+\mathrm{K}+$-ATPase inhibition and affords histological neuroprotection to male rats receiving cerebral global ischemia. Neurol Res. 2014;36(3):198-206. doi: 10.1179/1743132813y.0000000286.

46. Shambayati M, Patel M, Ma Y, Cunningham RL, Schreihofer DA. Central inflammatory response to experimental stroke is inhibited by a neuroprotective dose of dietary soy. Brain Res. 2014;1593:76-82. doi: 10.1016/j.brainres.2014.09.042.

47. Vafaee F, Hosseini M, Sadeghinia HR, Hadjzadeh MA, Soukhtanloo M, Rahimi M. The effects of soy extract on spatial learning and memory damage induced by global ischemia in ovariectomised rats. Malays J Med Sci. 2014;21(3):19-30.

48. Schreihofer DA, Redmond L. Soy phytoestrogens are neuroprotective against stroke-like injury in vitro. Neuroscience. 2009;158(2):602-9. doi: 10.1016/j. neuroscience.2008.10.003. 